\title{
Instrumento para Diagnóstico Institucional visando o Planejamento Estratégico de TI em Instituições Federais de Ensino Superior
}

\author{
Luiza Gonçalves de Paula' ${ }^{1,}$ Asterio Tanaka ${ }^{1}$, Renata Araujo ${ }^{1}$ \\ ${ }^{1}$ Departamento de Informática Aplicada - Universidade Federal do Estado do Rio de \\ Janeiro (UNIRIO) \\ \{luiza.paula, tanaka, renata.araujo\}@uniriotec.br
}

\begin{abstract}
This article presents the results of the first stage of an action research cycle for IT strategic planning in a public university, UNIRIO, in this case. The article shows the elaboration of an instrument for organizational diagnosis, its application and it's results interpretation. The instrument disclosed the IT users main dissatisfactions, the knowledge gaps between the IT committee members, the monitoring level of university's internal and external factors and the IT strategic planning main obstacles. This information points out the research environment, detaching the strengths and weaknesses for IT strategic planning execution.
\end{abstract}

Resumo. Este artigo apresenta os resultados da primeira etapa do ciclo da pesquisaação para a formulação do planejamento estratégico de TI em uma instituição federal de ensino superior, no caso a UNIRIO. O artigo apresenta a elaboração do instrumento para o diagnóstico institucional construído para a pesquisa, sua aplicação e a interpretação de resultados. $O$ instrumento revelou as principais insatisfações dos usuários com a TI, as lacunas de conhecimento dos membros do comitê de TI, o nível de monitoramento dos fatores internos e externos à universidade e os maiores empecilhos à elaboração do planejamento estratégico de TI. Estas informações caracterizam o ambiente da pesquisa, destacando as forças e fraquezas existentes para a elaboração do PETI.

\section{Introdução}

Apesar do entendimento de que o planejamento é um princípio fundamental da Administração Pública e das normas legais, em levantamento do Tribunal de Contas da União (TCU) sobre a governança de Tecnologia da Informação (TI) na Administração Pública Federal (Brasil. Tribunal de Contas da União,2008c) realizado em 2007, foi constatado que $47 \%$ dos 255 órgãos consultados não possuíam planejamento estratégico institucional em vigor. Nos $53 \%$ que possuíam planejamento estratégico em vigor, $40 \%$ destes não possuíam planejamento estratégico de TI.

A Estratégia Geral de Tecnologia da Informação (EGTI) foi emitida pela primeira vez em 2008 pelo Sistema de Administração dos Recursos de Informação e Informática da Administração Pública Federal (SISP) como resposta aos achados do levantamento do TCU sobre a governança de TI nas organizações públicas. Tal documento estabeleceu como meta para 2009 a existência e uso efetivo de um plano diretor de tecnologia da informação (PDTI) (BRASIL.Ministério do Planejamento, Orçamento e Gestão,2008a). 
Em novo levantamento realizado em 2010 pelo TCU, foi constatado um aumento no percentual de órgãos que implantaram o planejamento estratégico institucional. Apesar desse avanço, com relação ao planejamento estratégico de TI, o TCU concluiu que as iniciativas empreendidas (tais como normas e ações de conscientização) tanto pelo próprio TCU quanto pelos órgãos governamentais superiores ainda não surtiram efeito relevante (BRASIL.Tribunal de Contas da União, 2010).

Se a lei obriga o planejamento e constata-se que os órgãos não cumprem a lei, concluise que há fatores restritivos no contexto dos órgãos públicos para o desenvolvimento do planejamento estratégico de TI. Nutt (2005 apud HENDRICK, 2003) sugere os seguintes fatores como restritivos ao planejamento estratégico nas organizações públicas: a) os pontos de vista dos líderes e as manipulações pelos grupos de interesse são por vezes mais importantes que as questões econômicas; b) o que constituí "bom desempenho" nas organizações públicas é argumentável; e c) as organizações públicas têm objetivos mais amplos e que são difíceis de compreender e medir.

No caso das instituições federais de ensino superior (IFES), Araújo (1996 apud ATHANÁZIO, 2010) sugere que além dos fatores mencionados acima, há ainda outros fatores que tendem a restringir o planejamento estratégico nestas instituições: a) as decisões são descentralizadas; b) coexistem concepções distintas da universidade; c) o poder é ambíguo e disperso; e c) há reduzida coordenação de tarefas.

Segundo Meyer Junior e Meyer (2004, apud ATHANÁZIO, 2010), as organizações universitárias, por sua complexidade, exigem sempre dos seus gestores criatividade na formulação de modelos e abordagens gerenciais que lhes permitam atuar em um contexto complexo de liberdade acadêmica, objetivos difusos e grande sensibilidade a fatores ambientais. Os autores ainda observam que os modelos gerenciais racionais e analíticos não têm ajudado os gestores universitários a lidar com o ambiente universitário.

Os fatores específicos restritivos mencionados acima restringem a aplicação direta das abordagens de planejamento estratégico de TI usuais nas IFES. Faz-se então necessária a elaboração de uma abordagem específica para o contexto universitário público.

O objetivo desta pesquisa é o de fundamentar os gestores públicos das instituições federais de ensino superior (IFES) sobre abordagens de formulação de planejamento estratégico de tecnologia de informação, levando em consideração a etapa de alinhamento estratégico. A questão investigada nesta pesquisa é expressa na seguinte pergunta: "que abordagens de formulação de planejamento estratégico de TI podem prover suporte adequado ao seu desenvolvimento nas instituições federais de ensino superior, alinhado com o planejamento estratégico institucional?’.

Este artigo apresenta alguns resultados da primeira etapa do ciclo da pesquisa-ação deste trabalho de pesquisa: a construção do instrumento de diagnóstico institucional, a aplicação e resultados do instrumento. Algumas abordagens e métodos encontrados na literatura para o planejamento estratégico de TI são apresentados na seção Planejamento Estratégico de TI. As fases previstas no trabalho de pesquisa e a abordagem inicial de solução do problema em estudo são descritas na seção Abordagem para Planejamento Estratégico de TI nas Instituições Federais de Ensino Superior. A seção Caracterização do Ambiente apresenta a organização em estudo, a elaboração, aplicação e resultados do 
instrumento de diagnóstico institucional. A seção Conclusão e Próximos Passos destaca a influência do ambiente da pesquisa e as próximas fases do trabalho de pesquisa.

\section{Planejamento Estratégico de Tecnologia da Informação}

Affeldt e Vanti (2009) definem o planejamento estratégico de TI como sendo um conjunto de ferramentas e técnicas utilizadas para a identificação de elementos na área de TI que possibilitam apoiar os negócios empresariais e desenvolvimento de arquiteturas de informação, objetivos, estratégias e aplicações estratégicas. As ferramentas e técnicas utilizadas devem basear-se nas necessidades dos usuários da TI, sendo o resultado do processo um plano formal, semelhante ao planejamento estratégico institucional, para a área de TI.

No planejamento estratégico de TI, à semelhança do estabelecido por Pereira (2010) para o planejamento estratégico institucional, haveria três momentos: 1) o diagnóstico estratégico de TI, incluindo o alinhamento de TI com o negócio, 2) a formulação do planejamento estratégico de TI, e 3) a implementação e o controle do processo de planejamento estratégico de TI.

Luftman e Brier (1999, apud REZENDE, 2003) observam que o alinhamento entre o planejamento estratégico institucional e o planejamento estratégico de TI é um processo contínuo e complexo. Também destacam que não há uma só estratégia ou uma só combinação de atividades que permitam às organizações alcançar e sustentar esse alinhamento, pois são fatores em conjunto que levam ao sucesso dessa atividade.

Não há uma abordagem única para desenvolver o planejamento estratégico de TI. Cada organização possui um conjunto de características singulares que devem ser observadas para a definição de uma abordagem adequada de planejamento estratégico de TI naquele contexto. A seguir, esta proposta destaca algumas abordagens de planejamento estratégico de TI encontrados na literatura.

\section{1 - Abordagens de Planejamento Estratégico de TI}

Zambalde et al (2010) propõem um método para a implementação da governança de TI através do planejamento estratégico de TI que envolve 5 fases. A fase 1 (alinhamento da TI com o negócio) destina-se ao entendimento do contexto organizacional, definição de objetivos de negócio e de TI. A fase 2 (avaliação de desempenho e capacidade) destina-se à verificação da capacidade atual da TI na organização. A fase 3 (planejamento estratégico de TI) destina-se à definição de indicadores para medição do alcance a objetivos e da eficiência de processos críticos, de ações estratégicas que devem cobrir a eliminação ou atenuação de lacunas identificadas na fase 2 e a composição do Balanced Scorecard da TI. Na fase 4 (planejamento tático de TI) são formulados os planos de ação (planos táticos) para o alcance das estratégias de TI e do negócio. Por fim, na fase 5 (socialização e encerramento) são validados e disseminados os resultados do planejamento.

Bryson (2004) definiu uma abordagem para planejamento estratégico público com as seguintes fases: Fase 1) Iniciar e acordar o processo de planejamento estratégico; Fase 2) Identificar as incumbências organizacionais; Fase 3) Esclarecer a missão e valores organizacionais; Fase 4) Avaliar os ambientes interno e externo para identificar forças, fraquezas, oportunidades e ameaças; Fase 5) Identificar questões estratégicas 
enfrentadas pela organização; Fase 6) Formular estratégias para administrar as questões; Fase 7) Rever e adotar as estratégias ou o plano estratégico; Fase 8) Estabelecer uma visão organizacional efetiva; Fase 9) Desenvolver um processo de implementação efetivo; Fase 10) Reavaliar as estratégias e o processo de planejamento estratégico. Por tratar questões públicas, acredita-se que a abordagem contribuiria também no planejamento estratégico de TI público. No entanto, a esta abordagem falta uma etapa importante de alinhamento de TI com o negócio, prevista no método de Zambalde et al (2010).

O SISP preparou um guia do processo de elaboração de Plano Diretor de Tecnologia da Informação (PDTI). Este guia define 3 processos: 1) processo de preparação, com a definição da abrangência, período e metodologia do PDTI e alinhamento estratégico; 2) processo de diagnóstico, com a avaliação do referencial estratégico de TI, análise SWOT da TI organizacional, identificação dos fatores críticos de sucesso e avaliação das necessidades; e 3) processo de planejamento, com a priorização das necessidades inventariadas, definição de metas/ações, planejamento das ações de pessoal e submissão das minutas de PDTI à autoridade máxima da organização.

\section{Abordagem para Planejamento Estratégico de TI nas Instituições Federais de Ensino Superior}

As abordagens de planejamento estratégico de TI apresentados na seção anterior são genéricos. Não possuem mecanismos para tratar o poder ambíguo e disperso predominante nas instituições federais de ensino superior, nem o fator político que permeia o processo decisório nestas organizações.

Por não contemplarem as complexidades apresentadas no ambiente das universidades, estes métodos e modelos não são adequados à organização em estudo, não resolvendo, portanto, o problema de uma abordagem adequada de planejamento estratégico de TI voltado para as instituições federais de ensino superior.

O objetivo desta pesquisa é elaborar uma abordagem de planejamento estratégico de TI para IFES que contemple tanto os aspectos de planejamento estratégico público (Bryson, 2004), quanto aspectos de planejamento estratégico de TI (Zambalde et al, 2010). Esta abordagem será construída através de pesquisa-ação na UNIRIO.

A pesquisa-ação trata questões de natureza social e comportamental e tem seu foco na investigação das questões de pesquisa para compreensão do problema/solução dentro de seu contexto, e não na verificação de uma hipótese (Stringer , 2007).

Esta pesquisa-ação se desenvolverá com as seguintes etapas:

-Planejar: pretende-se avaliar, através da elaboração de questionários, a situação dos fatores que realmente influenciam o planejamento estratégico de TI na organização, tais como mudanças organizacionais, sinergia entre os colaboradores e percepções sobre a área de TI da instituição. Estes fatores caracterizam o ambiente da pesquisa e fornecem subsídios para as etapas posteriores. Após a caracterização do ambiente, será realizada a análise das abordagens de planejamento estratégico de TI existentes e será criado um modelo de PETI adaptado à realidade da organização em estudo. Este trabalho de pesquisa busca auxiliar no desenvolvimento de uma abordagem de planejamento estratégico de TI que contemple tanto métodos de planejamento estratégico público (Bryson, 2004) quanto métodos de planejamento estratégico de TI (Zambalde, 2010). A 
proposta do SISP para elaboração do PDTI também influenciará na definição da abordagem.

-Agir: A abordagem de planejamento estratégico de TI elaborada será aplicada, tendo como principal resultado o PDTI.

- Observar: Os dados gerados (dificuldades encontradas, lacunas, opiniões, justificativas, decisões, acordos, etc) através da aplicação da abordagem de PETI serão coletados.

-Refletir: As reflexões sobre os efeitos decorrentes da aplicação da abordagem e identificação de possíveis melhorias serão discutidas nesta etapa.

Este artigo apresenta os resultados da primeira etapa do ciclo da pesquisa-ação: a construção do instrumento de diagnóstico institucional, sua aplicação e discussão de resultados.

\section{Caracterização do Ambiente}

A pesquisa está sendo realizada na Universidade Federal do Estado do Rio de Janeiro (UNIRIO). A UNIRIO é uma organização seccional, pertencente ao órgão setorial Ministério da Educação, dentro da estrutura organizacional do SISP. A UNIRIO foi criada em 5 de junho de 1979, pela Lei ${ }^{\circ}$. 6.655. Conta com aproximadamente 1.700 funcionários e 15.000 alunos. Possui quatro unidades físicas, cinco unidades acadêmicas, cinco pró-reitorias e sete órgãos suplementares diretamente subordinados à Reitoria. As instâncias máximas de deliberação são Conselhos Superiores compostos por representações de todos os segmentos da comunidade, inclusive externa. São ofertados à sociedade aproximadamente 140 cursos, entre graduação, especialização, mestrado, doutorado, residência e extensão.

A UNIRIO está no processo de realizar seu planejamento estratégico de TI, tendo para isto constituído um Comitê de Tecnologia de Informação e Comunicação. A estrutura da área de TI da UNIRIO está dividida em Direção, Secretaria, Setor de Atendimento a Usuários, Coordenadoria de Infra-estrutura e Suporte, e Coordenadoria de Sistemas de Informação. A área de TI conta atualmente com 20 funcionários no total.

Os principais serviços fornecidos pela área de TI da UNIRIO são suporte técnico aos usuários de TI; compra/manutenção de hardware e software; desenvolvimento e manutenção de sistemas de informação e comunicação para as áreas administrativas e acadêmicas, além de apoio na criação/manutenção dos portais institucionais.

O Sistema de Informações para o Ensino (SIE) está em operação com o seu módulo acadêmico e em fase de implantação dos seguintes módulos administrativos: protocolo, administração orçamentária e financeira, recursos humanos, espaço físico, controle patrimonial, frota, materiais e almoxarifado, licitações e compras, assistência estudantil, processo seletivo e biblioteca.

Um comitê de TI foi estabelecido com a principal atribuição de elaborar o PDTI da instituição. Para apoiar os trabalhos do comitê de TI estabelecido, era necessário criar um instrumento que pudesse caracterizar o próprio comitê e as implicações que tais características trazem ao processo de planejamento estratégico de TI. Os participantes foram indicados como representantes dos diversos setores da universidade, o que leva a uma grande diversidade de visões e percepções da organização. 


\section{1 - Elaboração do Questionário}

O questionário foi elaborado buscando-se obter as percepções dos participantes do Comitê de TI em quatro áreas: satisfação dos usuários com a TI da UNIRIO, conhecimento individual dos participantes em ferramentas de planejamento estratégico e controles institucionais; fatores ambientais da UNIRIO e percepções quanto ao planejamento estratégico de TI. O questionário elaborado pode ser obtido no link http://www.dtic.unirio.br/dtic/ctic/documentos/documentos-do-ctic .

Uma das bases para o desenvolvimento do questionário foi o questionário produzido por Hendrick (2003), que buscava identificar se as variáveis por ela levantadas influenciavam ou não o processo de planejamento estratégico em organizações públicas.

Outro documento que foi utilizado como referência para a elaboração do instrumento foi a Portaria ${ }^{\circ}$. 11, de 30 de Dezembro de 2008 da Secretaria de Logística e Tecnologia da Informação do Ministério do Planejamento, Orçamento e Gestão (BRASIL, Ministério do Planejamento, Orçamento e Gestão, 2008b). Na portaria publicada no Diário Oficial da União havia um questionário que foi aplicado nos órgãos da Administração Pública Federal para levantamento da situação da governança de TI.

O questionário elaborado possui 11 questões, organizadas em 4 seções na seguinte ordem: 1) satisfação dos usuários com a TI na UNIRIO: as perguntas desta seção permitiram identificar os pontos onde a comunidade reconhece que pode haver melhorias na área de TI; 2) conhecimento individual dos participantes em ferramentas de planejamento estratégico e controles institucionais: o objetivo das perguntas desta seção era o de identificar o grau de conhecimento dos participantes em ferramentas e técnicas de planejamento estratégico que serão utilizadas nas próximas etapas do planejamento estratégico; 3) fatores ambientais da UNIRIO; as perguntas desta seção são importantes para identificar fatores que podem ter influência no planejamento estratégico de TI, como mudanças organizacionais e monitoração de fatores externos à UNIRIO; e 4) percepções quanto ao planejamento estratégico de TI na UNIRIO: as perguntas desta seção buscaram identificar a importância do planejamento estratégico de TI para os participantes do comitê e quais seriam os empecilhos para sua elaboração.

\section{2 - Aplicação do Questionário e Resultados}

O questionário foi aplicado com o comitê de TI da UNIRIO, totalizando 12 participantes. Foi explicado aos participantes que as respostas do questionário seriam mantidas de forma confidencial e que apenas o resultado geral seria publicado. Cada participante recebeu um link para que pudesse responder o questionário. Todos os participantes do comitê responderam o questionário em um período de 3 semanas.

A pergunta 1 buscou obter o grau de satisfação dos participantes do comitê quanto aos serviços fornecidos pela TI, em uma escala que ia de 1 (Muito Insatisfeito) a 5 (Muito Satisfeito). O resultado está apresentado no gráfico a seguir: 


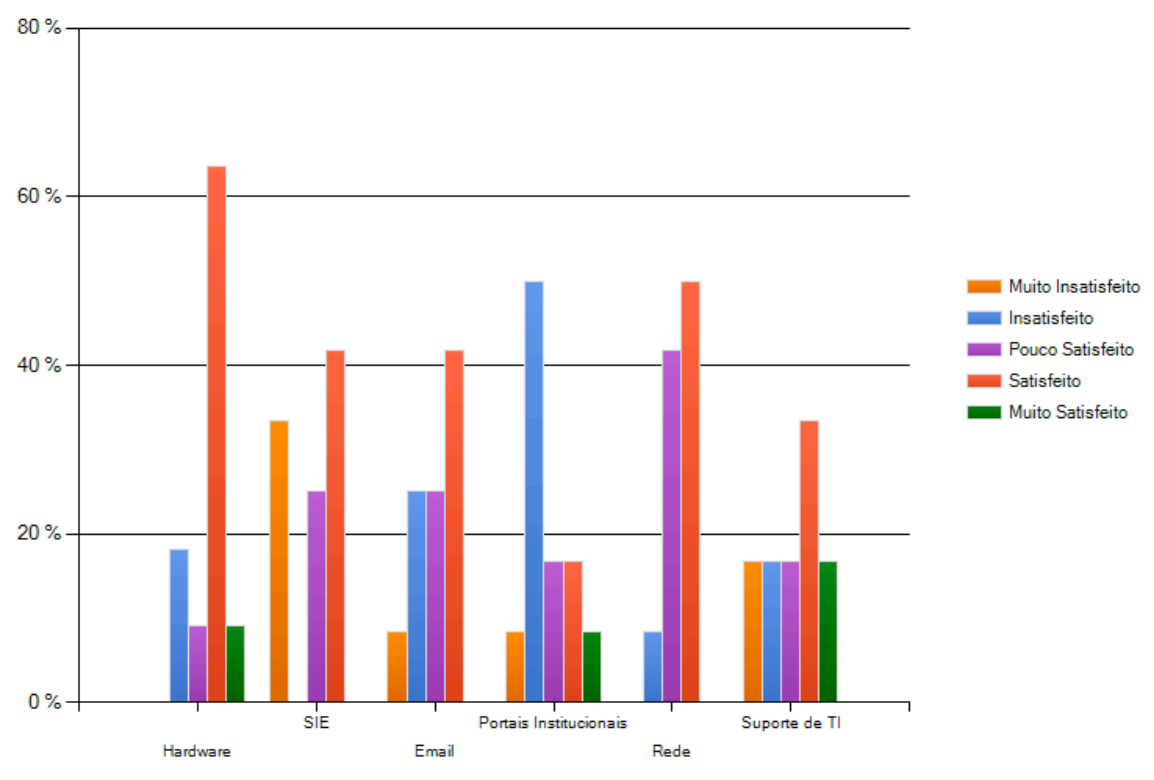

Gráfico 1 :Satisfação dos Usuários com a TI

A pergunta 3 buscou obter o grau de conhecimento dos participantes nas ferramentas e técnicas que normalmente são utilizadas em planejamento estratégico de TI, em uma escala que ia de 1 (Não Conheço) a 5 (Sou especialista). O resultado está apresentado no gráfico a seguir:

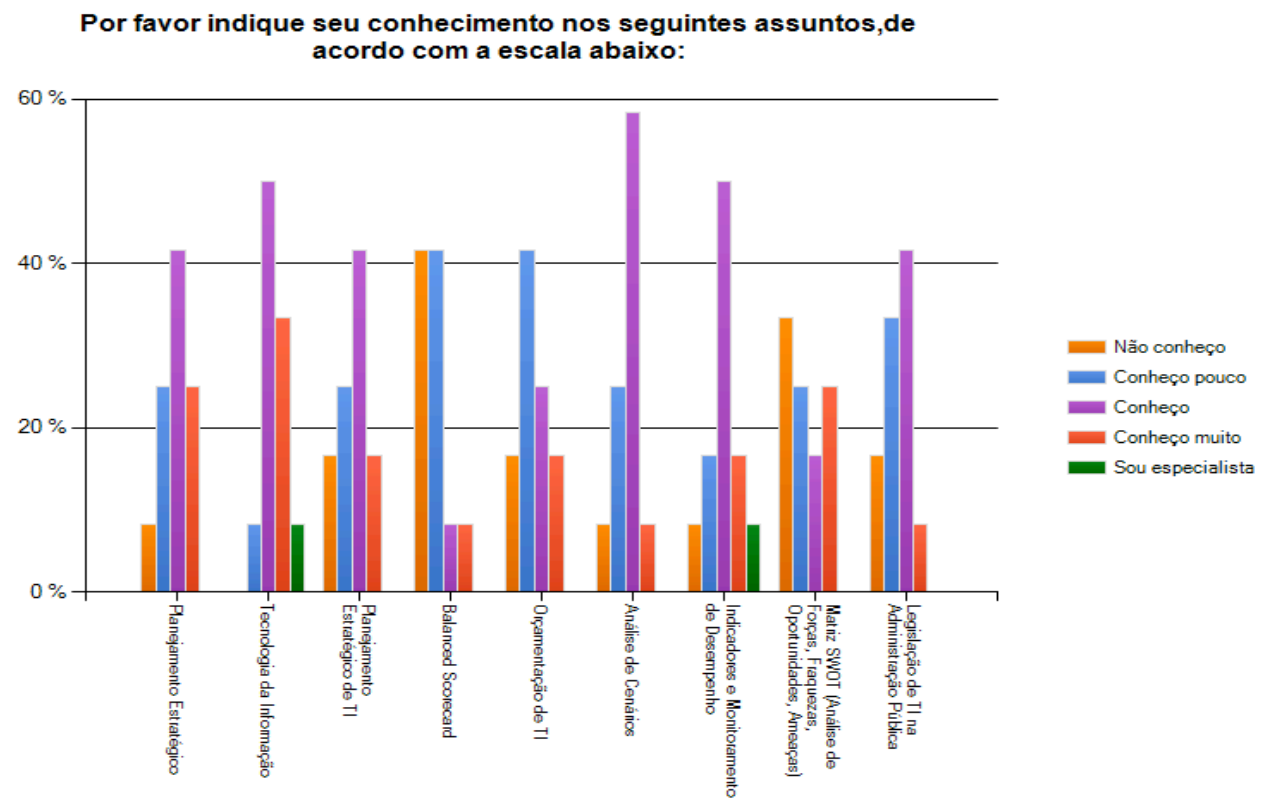

Gráfico 2 : Conhecimentos em Ferramentas e Técnicas de Planejamento Estratégico

Na pergunta 4 observou-se que quase a metade dos participantes, 41,7 \%, não conhece ou conhece pouco o Plano de Desenvolvimento Institucional (PDI), principal documento que irá apoiar na construção do PETI. 


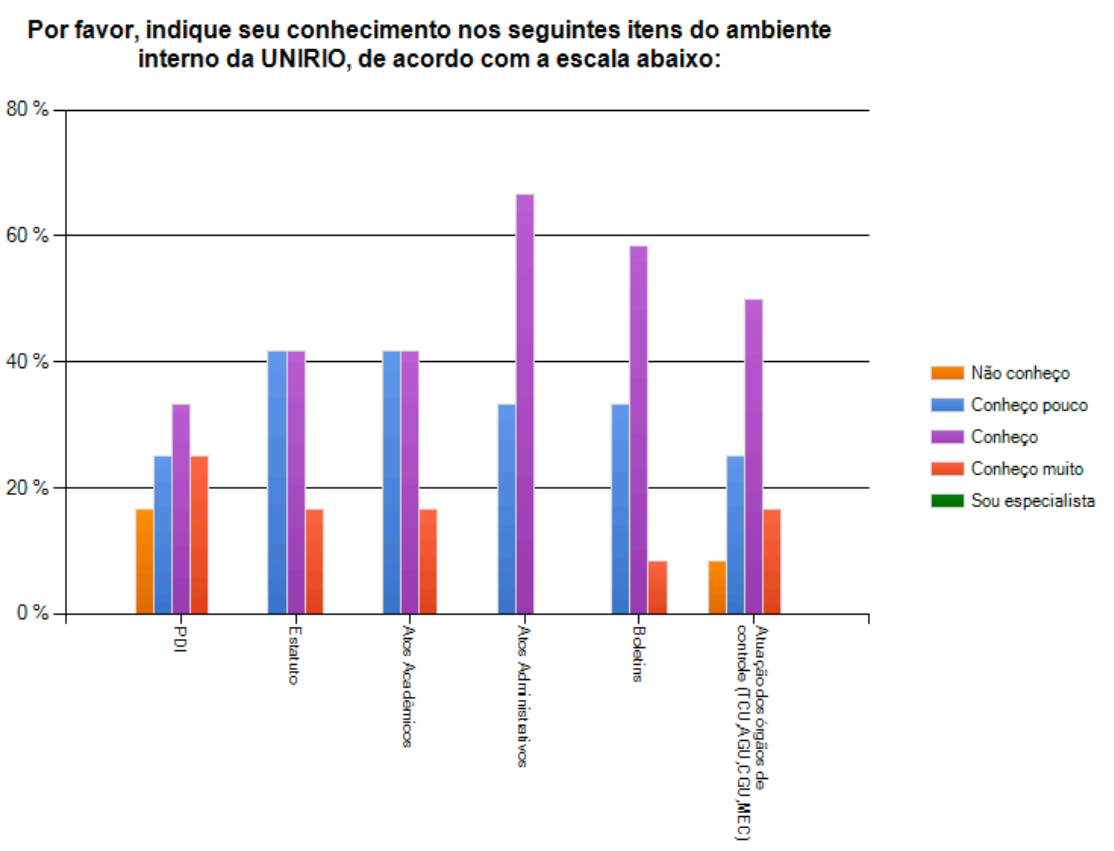

Gráfico 3 : Conhecimentos em Ativos de Processos Organizacionais

As mudanças organizacionais foram pesquisadas na pergunta 5. Nesta pergunta o resultado foi o apresentado no gráfico a seguir:

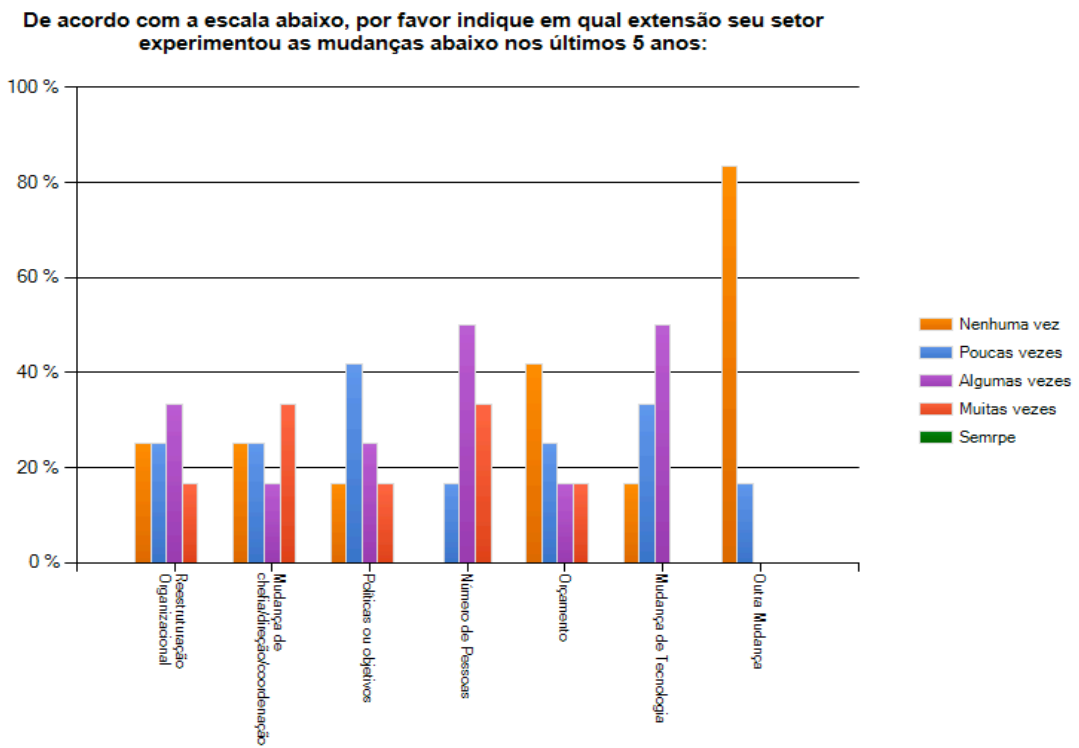

Gráfico 4: Mudanças Organizacionais

Em relação a monitoração dos fatores externos à organização na pergunta 6 , observouse que há pouca monitoração destes fatores, sendo a satisfação da sociedade o fator menos monitorado. 


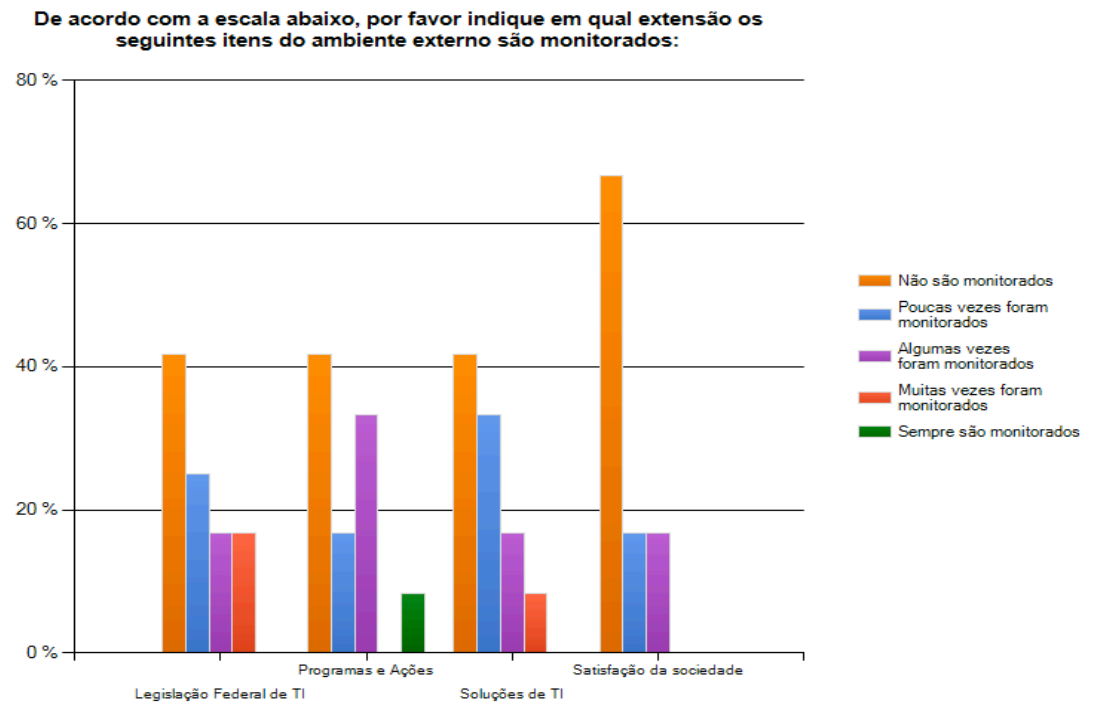

Gráfico 5: Monitoração dos Fatores Externos

Quando perguntados sobre a sinergia entre as pessoas na organização na pergunta na pergunta $7,50 \%$ dos participantes responderam que há pouca colaboração entre as pessoas e que poucas informações são compartilhadas.

A pergunta 8 sobre a definição de prioridades de TI, mostrou que 58,3\% dos respondentes acreditam que há prioridades estabelecidas para TI, mas que elas não foram comunicadas.

Um empate ocorreu na pergunta 9 sobre a definição dos papéis e responsabilidades da área de TI. Metade acredita que os papéis e responsabilidades estão estabelecidos e metade acredita que não.

As respostas da pergunta 10 mostraram que a maioria dos participantes, 83,3\%, acreditam que a elaboração do planejamento estratégico de TI para a UNIRIO seja indispensável.

Quando perguntados na pergunta 11 sobre quais seriam os maiores empecilhos para se desenvolver o planejamento estratégico de TI, a maioria dos participantes, $75 \%$, responderam ser a falta de um método adequado à realidade da UNIRIO, seguido por não saber como fazer, conforme mostra a figura a seguir:

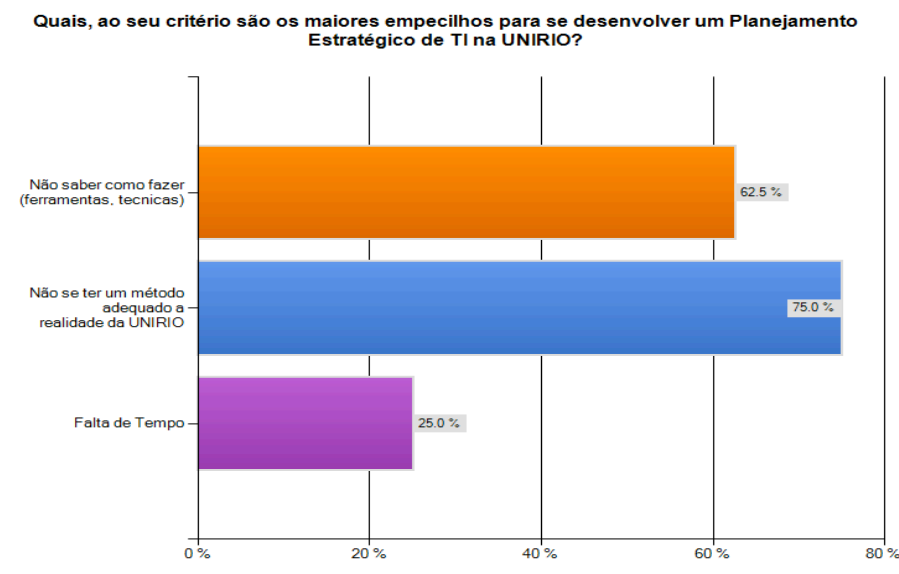

Gráfico 6: Empecilhos ao Planejamento Estratégico de TI 


\section{3 - Discussão dos resultados}

As maiores insatisfações percebidas em relação à área de TI são em relação ao Sistema de Informação para o Ensino (SIE) e Portais Institucionais. Foi discutido pelo comitê que a missão da área de TI reflete uma postura que seria mais de suporte à infraestrutura que de suporte à informação. Ficou decidido que a missão da área de TI deverá ser revista para que passe a atender às novas demandas da instituição.

As respostas à pergunta 2 evidenciaram a demanda por suporte aos portais institucionais. Quando perguntados se haveria algum serviço que poderia ser fornecido pela TI e que não era oferecido atualmente, $83,3 \%$ dos participantes responderam que sim e em sua maioria complementaram que os serviços que poderiam ser fornecidos pela TI seriam suporte para desenvolvimento de portais e sua efetiva implementação.

As ferramentas e técnicas menos conhecidas pelo comitê são o Balanced Scorecard (Kaplan e Norton, 1997) e a Matriz SWOT. A ferramenta escolhida para fazer a gestão da estratégia na UNIRIO foi o Geplanes (2010), um software público que é baseado no Balanced Scorecard. O cenário apresentado nas respostas desta pergunta evidenciaram a necessidade de capacitação em Balanced Scorecard e matriz SWOT.

Pode-se inferir que o tipo de mudança que mais ocorre nos setores da universidade é o número de pessoas, seguido pela mudança de chefia/direção/coordenação. Uma grande quantidade de mudanças em chefia/direção/coordenação implicará em possíveis revisões de prioridades pelos novos gestores e, consequentemente, no planejamento estratégico de TI.

Em relação à definição dos papéis e responsabilidades, existe o regimento da área de TI, mas evidencia-se que apenas a metade dos participantes conhecia tal documento.

A maioria dos participantes do comitê de TI confirma o exposto na seção Abordagem para Planejamento Estratégico de TI para Instituições Federais de Ensino Superior: não há uma abordagem ou método de planejamento estratégico de TI adequado à realidade da UNIRIO.

\section{Conclusão e Próximos Passos}

No presente artigo foram apresentados alguns resultados da etapa de planejamento da pesquisa-ação sobre formulação do planejamento estratégico de TI em instituições federais de ensino superior: a construção do instrumento de diagnóstico institucional, a aplicação e resultados do instrumento.

Foi relatado como ponto de melhoria para uma próxima aplicação do instrumento que a questão 7 fosse desmembrada em duas. Foi relatado que a conjunção "e" causou uma certa dificuldade na escolha da resposta. Outro ponto de melhoria no questionário seria incluir como pergunta o tempo de trabalho na organização. Foi levantado que isto poderia influenciar na resposta da pergunta 5,pois dependendo do tempo de trabalho na organização, alguns poderiam ter passado por cenários diferentes.

O comitê de TI reconheceu os resultados do questionário como válidos e importantes para subsidiar as tarefas futuras a serem realizadas. O questionário revelou as principais insatisfações dos usuários com a TI, as lacunas de conhecimento dos membros do 
comitê de TI, o nível de monitoramento dos fatores internos e externos à universidade e os maiores empecilhos à elaboração do planejamento estratégico de TI. Estas informações caracterizam o ambiente da pesquisa, destacando as forças e fraquezas existentes para a elaboração do PETI.

Segundo Herr e Anderson (2005), a pesquisa-ação pode resultar em produtos e instrumentos que podem ser utilizados em outros contextos. Espera-se que os resultados da pesquisa a serem apresentados (dados, documentos, análises, procedimentos e reflexões sobre o processo de formulação do planejamento estratégico de TI) possam ser utilizados em outras instituições federais de ensino que estejam no momento de formulação do planejamento estratégico de TI, atendendo assim a característica científica da validade externa.

O próximo passo da pesquisa, ainda dentro da etapa de planejar da pesquisa-ação, é a estruturação do método de PETI proposto e sua posterior aplicação na etapa de ação, que terá como principal resultado o PDTI.

\section{Agradecimentos}

Este trabalho está inserido no contexto do projeto Democracia, Transparência e Administração Pública (http://www.uniriotec.br/ agora), financiado pela CAPES e no contexto do Instituto Brasileiro de Pesquisa em Ciência da Web - CNPq 557.128/2009-9 e FAPERJ E-26/170028/2008. Renata Araujo é bolsista de produtividade do CNPq.

Agradecemos ao diretor da Diretoria de Tecnologia da Informação (DTIC) da UNIRIO, Ademir Dias Lima, que auxiliou na elaboração do questionário e aos membros do Comitê de Tecnologia da Informação (CTIC) que participaram respondendo o questionário.

\section{Referências Bibliográficas}

AFFELDT, F.S. VANTI A. A. Alinhamento Estratégico de Tecnologia da Informação: Análise de Modelos e Propostas para Pesquisas Futuras. Journal of Information Systems and Technology Management. Vol. 6, No. 2, p. 203-226, 2009

ATHANÁZIO, Madeleine Mônica. "Processo de Planejamento Estratégico em Universidade Pública: O Caso da Universidade Federal do Pará.” 153 p. Dissertação (Mestrado em Administração). Universidade Federal do Rio Grande do Norte, 2010

ARAÚJO, Maria Arlete Duarte de. Planejamento estratégico: um instrumental à disposição das universidades? Revista de Administração Pública. Rio de Janeiro, FGV, 30(4): 74-86, jul./ago.1996.

BRASIL.Ministério Do Orçamento, Planejamento E Gestão. "Estratégia Geral de Tecnologia da Informação". Brasília, DF, 2008a. Disponível em $<$ http://www.governoeletronico.gov.br/sisp-conteudo/estrategia-geral-de-ti> Acesso em 01 nov 2010.

BRASIL. Ministério do Orçamento, Planejamento e Gestão. Portaria n . 11, de 30 de dezembro de 2008. Diário Oficial da União. Dezembro, 2008b

BRASIL. Tribunal de Contas da União. Levantamento acerca da Governança em Tecnologia da Informação na Administração Pública Federal. Brasília : TCU, 2008c. Disponível

em< 
http://portal2.tcu.gov.br/portal/page/portal/TCU/comunidades/tecnologia_informacao/su marios/Sumario_Governan\%C3\%A7a\%20em\%20TI_miolo.pdf> . Acesso em 01 out. 2010

BRASIL.Tribunal de Contas da União. Levantamento sobre Governança em Tecnologia da Informação na Administração Pública Federal. Brasília : TCU, 2010. Disponível << http://portal2.tcu.gov.br/portal/page/portal/TCU/comunidades/tecnologia_informacao/pe $\begin{array}{lllll}\text { squisas_governanca> } & \text { Acesso } & \text { em } & 10 & \text { out. }\end{array}$ BRYSON, J. M. "Strategic Planning for Public and Nonprofit Organizations: A Guide for Strengthening and Sustaining Organizational Achievement" . USA: Jossey - Bass, 2004 - 3rd ed.

GEPLANES. Software Gratuito de Gestão Estratégica . Disponível em http://www.geplanes.com.br.. Acesso em 10 jan 2011

HENDRICK, R. Strategic Planning Environmnent, Process, and Performance in Public Agencies : A Comparative Study of Departments in Milwaukee. Journal of Public Administration Research and Theory. v.13, n. 4, pág. 491-519, 2003

HERR, K., ANDERSON, G. L. "The Action Research Dissertation: A Guide for Students and Faculty". California : Sage Publications, 2005

KAPLAN, R.S ; NORTON, D.P. "A estratégia em ação : balanced scorecard.” Rio de Janeiro: Elsevier, 1997 - 24ª Reimpressão

LUFTMAN, J. N.; BRIER, T. "Achieving and sustaining business-IT alignment. “ California Management Review, Berkeley, v. 42, p. 109-122, Fall 1999.

MEYER JR, Victor; MEYER, Bernardo. Planejamento estratégico nas instituições de ensino superior: técnica ou arte? In: IV Colóquio Internacional sobre Gestão Universitária na América do Sul. Florianópolis, dezembro, 2004.

NUTT, P. C. Comparing Public and Private Sector Decision-Making Practices . Journal of Public Administration Research and Theory. v.16,pág. 289-318, 2005

PEREIRA, M.F. "Planejamento estratégico : teorias, modelos e processo." São Paulo: Editora Atlas, 2010

REZENDE, Denis Alcides .Metodologia para projeto de planejamento estratégico de informações alinhado ao planejamento estratégico : a experiência do Senac-PR. Ciência da Informação, Brasília, v. 32, n. 3, p. 146-155, set./dez. 2003

STRINGER. E. T. “Action Research.” California : Sage Publications, 2007 - 3rd Edition

ZAMBALDE, André Luiz et al. Implementação da governança de tecnologia da informação através do planejamento estratégico de TI. CONFENIS. IV INTERNACIONAL CONFERENCE ON RESEARCH AND PRATICAL ISSUES OF ENTERPRISE INFORMATION SYSTEMS. Anais...Natal: Ministério da Educação do Brasil, 2010. 1 CD-ROM. 